\title{
O quadro de trabalhadores federais em saúde no Brasil: uma análise no contexto dos anos 2000
}

\author{
| ${ }^{1}$ Luciane Galdino Alberto, ${ }^{2}$ Cristiani Vieira Machado, ${ }^{3}$ Márcia Teixeira |
}

Resumo: O artigo analisa o quadro de trabalhadores do Ministério da Saúde e entidades vinculadas - agências reguladoras da saúde e Fundação Oswaldo Cruz - de 2000 a 2008, relacionando a evolução quantitativa e o perfil dos vínculos dos trabalhadores federais da saúde com os condicionantes históricos e as políticas para o funcionalismo. As estratégias metodológicas da pesquisa foram: revisão bibliográfica, análise documental e de dados primários e secundários. Os resultados sugerem que a partir de 2003 houve uma recomposição parcial de quadros na administração pública federal, por meio de concursos públicos. Tal movimento foi heterogêneo entre áreas, sendo que a saúde apresentou um aumento de servidores ativos inferior à média federal. Observaram-se diferenças na situação do quadro de trabalhadores do Ministério da Saúde e entidades vinculadas. O nível central do Ministério foi pouco beneficiado com a realização de concursos, mantendo baixa proporção de servidores e alta dependência de consultores, terceirizados e contratos temporários. As agências reguladoras da saúde receberam servidores concursados a partir de 2005, mas em 2008 ainda apresentavam trabalhadores com outros tipos de vínculos. $\mathrm{Na}$ Fiocruz, observou-se um incremento do número de servidores, porém um aumento maior dos terceirizados. Por fim, discutem-se os desafios de conformação de uma adequada força de trabalho no Ministério da Saúde e entidades vinculadas, visto que no Brasil a esfera federal mantém um papel estratégico para a consolidação do Sistema Único de Saúde.

\author{
1 Administradora; mestre \\ em Políticas Públicas pela \\ ENSP/Fiocruz; servidora da \\ Coordenação de Recursos \\ Humanos do INCQS/Fiocruz. \\ Endereço eletrônico: luciane. \\ alberto@incqs.fiocruz.br \\ ${ }^{2}$ Médica sanitarista; doutora \\ em Saúde Coletiva pelo IMS/ \\ UERJ; professora e pesquisadora \\ do Departamento de \\ Administração e Planejamento \\ em Saúde da ENSP/Fiocruz. \\ Endereço eletrônico: \\ cristiani@ensp.fiocruz.br \\ ${ }^{3}$ Socióloga; mestre em \\ Ciências da Saúde pela \\ ENSP/Fiocruz; pesquisadora \\ do Departamento de \\ Administração e Planejamento \\ em Saúde da ENSP/Fiocruz. \\ Endereço eletrônico: \\ txmarcia@hotmail.com
}




\section{Introdução}

As transformações mundiais nas últimas décadas, relacionadas à globalização, levaram a novas conformações dos mercados e das relaçoos de trabalho. Paralelamente, aumentaram as críticas ao Estado interventor e às estruturas burocráticas, vistas como problemas a serem solucionados. No entanto, após um período de hegemonia dos postulados neoliberais, observou-se uma nova onda de reformas, marcada pelo reconhecimento da importância estatal, o que tem levado a propostas de fortalecimento da capacidade institucional do Estado (EVANS, 1993).

As reformas recentes do Estado se expressaram de maneira distinta em cada país, de acordo com a sua história, seu legado institucional e as decisóes políticas dos governos e burocracias nacionais. O Brasil, principalmente a partir dos anos 1990, sofreu efeitos das transformações mundiais, com repercussóes sobre o mercado de trabalho, o papel do Estado e o perfil da administração pública. Porém, tais repercussões foram mediadas pela especificidade da trajetória do Estado brasileiro e por decisões tomadas pelos governos das últimas duas décadas.

A história da administração pública brasileira mostra algumas características marcantes. Em primeiro lugar, nunca houve a conformação de uma burocracia sólida e disseminada pelos vários setores de atuação estatal. Mesmo nos momentos de crescimento da intervenção estatal, observou-se a presença de uma força de trabalho composta por múltiplos vínculos, como demonstra Wahrlich (1983). Ademais, a evolução da administração não foi linear, ainda que em alguns momentos tenha se observado a conformação de burocracias mais sólidas, especialmente em áreas estratégicas para a economia, formando bolsões de eficiência (NUNES, 1997). Não houve um investimento expressivo na conformação de burocracias na área social, incluindo a área da saúde.

No contexto brasileiro dos anos 1980, marcado pela democratização e a promulgação da Constituição Federal em 1988, houve proposições relativas ao fortalecimento da atuação do Estado, relacionadas à ampliação dos direitos sociais. Porém, nos anos 1990, predominou no país uma agenda de reforma do Estado que defendia a redução do funcionalismo público e a configuração de um Estado regulador, com repercussões adversas para o setor público. Destacam-se nesse sentido a contenção de gastos com pessoal, a pouca disponibilidade de 
servidores para responderem às novas responsabilidades estatais e a proliferação

de vínculos precários na administração pública, nas três esferas de governo. Em consequência dessa agenda e do acentuado processo de descentralização, o funcionalismo federal apresentou, na década de 90, uma drástica retração (SANTOS, 2006; MORAES; SILVA; COSTA, 2009).

Isso ocorreu quando a instituição do Sistema Único de Saúde colocava novos desafios para a atuação do Estado na saúde nas três esferas de governo. A unificação do comando nacional da política de saúde sob responsabilidade do Ministério da Saúde ${ }^{1}$ e a descentralização político-administrativa requeriam uma profunda reconfiguração do papel federal. De fato, nos anos 1990, o Ministério passou por mudanças institucionais relevantes. Mesmo no contexto da descentralização, reafirmou-se sua importância na formulação de políticas, regulação do sistema de saúde e financiamento de suas açôes e serviços, em conjunto com as esferas estaduais e municipais. Houve retração da função federal de prestação direta de serviços, embora ainda existam unidades assistenciais ligadas ao ministério em alguns estados. Observaram-se ainda alterações na estrutura administrativa federal, que envolveram a criação, reformulação e extinção de órgãos e entidades da saúde (MACHADO, 2007).

Para o desempenho de novas e estratégicas funções federais na saúde, também seria importante a configuração de uma força de trabalho suficiente e adequada. Ao contrário disso, entre 1997 e 2003, ocorreu uma diminuição de 47 mil servidores ativos do Ministério da Saúde, o que representava 38\% do total (UNB, 2004). O contexto adverso levou ainda à configuração de um quadro híbrido no Ministério e entidades vinculadas, com a inclusão de trabalhadores com vínculos alternativos para assegurar o desempenho das atribuições estatais na política de saúde, um fenômeno observado no conjunto do setor (PIERANTONI, 2001).

Este artigo analisa a situação, nos anos 2000, do quadro de trabalhadores do Ministério da Saúde e entidades federais vinculadas, segundo variáveis selecionadas. A escassez de estudos recentes sobre o tema e a mudança do Governo Federal a partir de 2003 justifica o recorte temporal da pesquisa. Assim, busca-se apresentar a evolução quantitativa e o perfil de vínculos dos trabalhadores federais em unidades estratégicas, analisando-os à luz de elementos histórico-institucionais e do contexto recente da administração pública brasileira e da saúde. 
O estudo procurou mapear os dados gerais de evolução do funcionalismo federal da saúde de 2000 a 2008 e analisar em maior detalhe a situação de vínculo dos trabalhadores do nível central do Ministério da Saúde e de três entidades vinculadas: Agência Nacional de Vigilância Sanitária (ANVISA), Agência Nacional de Saúde Suplementar (ANS) e Fundação Oswaldo Cruz (Fiocruz).

A escolha dessas organizações se deve à sua relevância na definiçãoo de diretrizes estratégicas, na formulação e na regulação da política nacional de saúde no Brasil. Ainda que sejam apresentadas informações gerais sobre o funcionalismo da saúde, não foi analisada na pesquisa a situação de vínculo dos trabalhadores federais atuantes em núcleos estaduais do Ministério da Saúde; em hospitais federais; na Fundação Nacional da Saúde (FUNASA); e cedidos a outras esferas de governo².

A pesquisa partiu do referencial teórico do institucionalismo histórico, que salienta a causalidade social como dependente da trajetória percorrida (path dependence) e combina explicaçôes relativas à importância das instituições com a valorização das conjunturas políticas (HALL E TAYLOR, 2003). As categorias de análise privilegiadas na pesquisa foram: a trajetória institucional e o contexto atual das organizações estudadas, que são relevantes para a compreensão da situação atual do quadro de trabalhadores federais da saúde; e o tipo de vínculo que estes têm, que pode afetar tanto a estabilidade do órgão, quanto a continuidade da política nacional e o fortalecimento de um novo papel federal no SUS.

As principais estratégias metodológicas foram a revisão bibliográfica, análise de documentos oficiais e de dados primários e secundários do Governo Federal relativos à força de trabalho em saúde no período de 2000 a 2008. Para o mapeamento de tendências do funcionalismo federal em geral e na saúde, foi importante autilização das publicaçôes do Ministério do Planejamento, Orçamento e Gestão (Boletim Estatístico de Pessoal e Síntese Temática). No entanto, para a identificação mais detalhada do perfil dos vínculos dos trabalhadores da saúde, foram analisados documentos oficiais (relatórios gerenciais) e dados obtidos das páginas ou fornecidos diretamente pelo Ministério da Saúde, ANVISA, ANS e Fiocruz. Ressalte-se que tais dados nem sempre estavam disponíveis para o conjunto do período estudado. No caso do nível central do Ministério, só foram obtidos dados detalhados por tipos de vínculos dos trabalhadores para o ano de 2007. No caso da ANVISA, não foram obtidos dados relativos aos consultores e trabalhadores terceirizados. 
Complementarmente, foram analisados os dados da execução orçamentária federal do Ministério da Saúde com pessoal de 2002 a 2008, disponíveis no Sistema de Informações sobre Planos e Orçamento Público (SIGA Brasil ${ }^{3}$ ). Essa fonte permite analisar a execução orçamentária total e discriminada por unidades orçamentárias do Ministério: o Fundo Nacional de Saúde (que abrange todos os órgãos da Administração Direta), a ANVISA, a ANS, a Fiocruz e a FUNASA.

A pesquisa foi conduzida dentro dos padrōes éticos exigidos pela Comissão Nacional de Ética em Pesquisa/Conselho Nacional de Saúde/Ministério da Saúde (CONEP/CNS/MS) e aprovada por Comitê de Ética da instituição de pesquisa responsável, conforme resolução no 196/96 do CNS.

\section{Resultados}

\section{O contexto do funcionalismo federal e a saúde}

A partir de 2003, o Governo Federal assumiu uma política de recomposição dos quadros de servidores federais ativos e de regularização das relações de trabalho no serviço público, o que envolveu a realização de vários concursos públicos entre 2003 e 2008 (BRASIL, 2009c). O número de servidores federais ativos passou de 486.912, em 2000, para 539.235, em 2008, correspondendo a um aumento de $10,7 \%$ (tabela 1 ).

Tabela 1: Evolução do quadro de servidores públicos federais civis ativos do Poder Executivo da Saúde, da Educação e Total - Brasil, 2000 a 2008.

\begin{tabular}{c|c|c|c|c|c}
\hline \multicolumn{2}{c|}{ Saúde } & \multicolumn{2}{c}{ Educação } & Total \\
\hline $\mathbf{A n o}$ & Quant. & $\begin{array}{c}\text { \% Saúde/ } \\
\text { Total }\end{array}$ & Quant. & $\begin{array}{c}\text { \% Educ/ } \\
\text { Total }\end{array}$ & Quant. \\
\hline $\mathbf{2 0 0 0}$ & 102.480 & 21,0 & 165.595 & 34,0 & 486.912 \\
\hline $\mathbf{2 0 0 1}$ & 104.948 & 21,6 & 163.479 & 33,7 & 485.303 \\
\hline $\mathbf{2 0 0 2}$ & 103.634 & 21,3 & 165.163 & 34,0 & 485.741 \\
\hline $\mathbf{2 0 0 3}$ & 105.238 & 21,7 & 164.870 & 33,9 & 485.980 \\
\hline $\mathbf{2 0 0 4}$ & 103.483 & 20,7 & 171.925 & 34,4 & 499.138 \\
\hline $\mathbf{2 0 0 5}$ & 106.079 & 20,8 & 173.181 & 34,0 & 508.963 \\
\hline $\mathbf{2 0 0 6}$ & 109.107 & 20,7 & 179.449 & 34,0 & 528.124 \\
\hline $\mathbf{2 0 0 7}$ & 106.259 & 20,1 & 180.895 & 34,2 & 528.420 \\
\hline $\mathbf{2 0 0 8}$ & 105.621 & 19,6 & 188.440 & 34,9 & 539.235 \\
\hline Var.\% 2000/2008 & $\mathbf{3 , 1}$ & & $\mathbf{1 3 , 8}$ & & $\mathbf{1 0 , 7}$ \\
\hline
\end{tabular}

Fonte: Boletim estatístico do MPOG, referente a dezembro de 2008. Elaboração dos autores. 
Entretanto, o quadro de servidores ativos não cresceu na mesma proporção dos ingressos por concurso, por conta das aposentadorias e evasões do serviço público (VIANA, 2009). Somente em 2008 a administração federal atingiu e ultrapassou o número de servidores ativos de 1997, que era de 531.725 (BRASIL, 2009c). Acrescente-se a isso que a recomposição dos servidores federais nos anos 2000, além de gradual, foi qualitativamente superior no que se refere ao perfil de escolaridade. Dos 91.419 concursados que ingressaram entre 2000 e 2008, 61,3\% eram de nível superior e 38,7\% de nível intermediário.

Tal movimento, no entanto, foi variado entre as áreas da administração. Como mostra a Tabela 1, as áreas da saúde e da educação, responsáveis por duas importantes políticas universais, apresentaram expansão do número de servidores ativos. Porém, esse aumento foi mais expressivo na educação, que passou de 165.595 servidores em 2000, para 188.440 em 2008 (crescimento de 13,8\%). Na saúde, o número de servidores variou no mesmo período de 102.480 para 105.621, um aumento de apenas 3,1\%. Essa diferença no crescimento também foi expressiva em termos absolutos, visto que o montante de servidores da educação é maior do que o da saúde. Além disso, há diferenças no perfil dos servidores das áreas. Em 2008, do total dos servidores federais, 40,8\% eram de nível de escolaridade superior e 47,6\% eram de nível intermediário. Na educação, $56,8 \%$ dos servidores possuía nível superior, o que provavelmente se relaciona ao grande número de professores e funcionários das universidades federais. Já na saúde, $60,2 \%$ dos servidores eram de nível intermediário, com um grande peso dos profissionais técnicos lotados nos hospitais federais (BRASIL, 2008a).

Quanto ao tipo de vínculo, o quadro de trabalhadores da saúde é composto por servidores efetivos, requisitados, nomeados sem vínculo, em exercício descentralizado, contratos temporários, consultores e terceirizados. Considerando somente os servidores permanentes ativos da saúde na administração direta (os da sede do Ministério da Saúde em Brasília, dos núcleos estaduais, hospitais e institutos) houve uma diminuição entre 2000 e 2008 de 64.076 para 51.601, ou seja, de 19,4\%. Já o número de profissionais com contratos temporários da União nessas unidades cresceu no mesmo período de 745 para 6.179 (BRASIL, 2008c). Apesar do aumento dessa modalidade, os contratados não substituíram os servidores em termos quantitativos. Além disso, o caráter temporário desse vínculo não assegura a estabilidade dos trabalhadores e a continuidade das 
políticas de saúde em longo prazo. Assinale-se que esses dados não incluem os consultores e terceirizados, nem os trabalhadores atuantes nas agências e fundações federais da saúde.

No que concerne à execução orçamentária da União, a despesa com pessoal reflete o quantitativo, a remuneração e as políticas destinadas aos servidores públicos. A análise da execução orçamentária do Ministério da Saúde com pessoal de 2002 a 2008 revela que a despesa com pessoal ativo cresceu $28,4 \%$ no período, um aumento próximo à variação no orçamento total desse ministério (28,3\%). Já os gastos com pensionistas e inativos no orçamento da saúde variaram apenas 1,7\% no período.

A tabela 2 mostra que a variação da execução orçamentária com pessoal ativo de 2002 a 2008 foi positivo para todas as unidades orçamentárias da saúde analisadas. Porém, o gasto com pessoal a partir do Fundo Nacional de Saúde, que abrange os servidores na administração direta, teve o menor aumento no período (somente 12,3\%). Já as agências reguladoras da saúde - ANVISA e ANS - tiveram aumentos de execução orçamentária com pessoal ativo de respectivamente $180,1 \%$ e $169,7 \%$ no período. A Fiocruz também teve um incremento expressivo das despesas com servidores ativos (89,2\%).

Tabela 2: Execução orçamentária com pessoal ativo segundo unidades orçamentárias do Ministério da Saúde, em valores ajustados pela inflação (para R \$ de dezembro de 2008)- Brasil, 2002 e 2008.

\begin{tabular}{l|r|r|c}
\multicolumn{1}{c|}{ Unidade } & \multicolumn{1}{c|}{$\mathbf{2 0 0 2}$} & \multicolumn{1}{c|}{$\mathbf{2 0 0 8}$} & \multicolumn{1}{c}{$\begin{array}{c}\text { VAR. \% } \\
\mathbf{2 0 0 2 - 2 0 0 8}\end{array}$} \\
\hline $\begin{array}{l}\text { Ministério da Saúde } \\
\text { (Fundo Nacional de Saúde) }\end{array}$ & 2.312 .788 .093 & 2.599 .341 .690 & 12,3 \\
\hline Agência Nacional de Vigilância Sanitária & 89.285 .447 & 250.172 .994 & 180,1 \\
\hline Agência Nacional de Saúde Suplementar & 25.715 .578 & 69.360 .984 & 169,7 \\
\hline Fundaçáo Oswaldo Cruz & 261.347 .502 & 494.686 .755 & 89,2 \\
\hline Fundaçáo Nacional da Saúde & 1.311 .319 .300 & 1.723 .306 .901 & \multicolumn{1}{c}{31,4} \\
\hline Total Geral & $\mathbf{4 . 0 0 0 . 4 5 5 . 9 2 1}$ & $\mathbf{5 . 1 3 6 . 8 6 9 . 3 2 4}$ & $\mathbf{2 8 , 4}$ \\
\hline
\end{tabular}

Fonte: Dados do SIGA Brasil - Senado Federal (2008). Elaboração dos autores.

(1) Os valores empenhados foram corrigidos pela inflação aferida pelo IPCA/IBGE, para valores em R \$ de dezembro de 2008.

(2) No cálculo só foi considerado o Grupo Nacional de Despesa "1" referente ao pagamento de folha de pessoal. 
Em face dessas diferenças e das especificidades de cada unidade, discute-se separadamente a situação dos trabalhadores do nível central do ministério, das agências reguladoras da saúde e da Fiocruz.

\section{Os trabalhadores do nível central do Ministério da Saúde}

O nível central do Ministério da Saúde em Brasília é responsável pela condução estratégica e pela coordenação da política nacional de saúde. A estrutura ministerial compreende, além do gabinete do ministro, um conjunto de órgãos de assessoria e de secretarias, que se desdobram em departamentos e coordenações.

A partir de 2003, houve mudanças na estrutura administrativa do Ministério da Saúde que representaram tentativas de redução da fragmentação e delineamento de um desenho institucional mais condizente com suas atribuições nos diversos campos de atenção à saúde (VIANA; MACHADO, 2008). Ao final de 2008, o nível central do Ministério em Brasília compreendia seis secretarias de primeiro escalão: a Executiva; a de Atenção à Saúde; a de Vigilância em Saúde; a de Ciência, Tecnologia e Insumos Estratégicos; a de Gestão do Trabalho e da Educação na Saúde; e a de Gestão Estratégica e Participativa.

O quadro de trabalhadores do nível central do Ministério da Saúde é composto por servidores efetivos, requisitados, nomeados sem vínculo, contratos temporários, consultores e terceirizados. Conforme demonstrado na Tabela 3, em 2007, somente 33\% desses trabalhadores eram servidores e $4 \%$ tinham contratos temporários. Em contrapartida, existia uma expressiva proporção de terceirizados (34\%) e de consultores (29\%), que, juntos, representavam 63\% do quadro de trabalhadores atuantes na sede do Ministério.

Ao se analisar a distribuição interna dos trabalhadores do núcleo central do ministério por áreas de lotação (secretarias e órgãos de assessoria), verifica-se uma grande variação entre áreas no que diz respeito à proporção de servidores permanentes e trabalhadores com outros vínculos. No entanto, em nenhuma das secretarias a proporção de servidores ultrapassou $50 \%$ dos trabalhadores, o que só foi observado em alguns órgãos de assessoria (tabela 3).

O quadro de trabalhadores da Secretaria de Atenção à Saúde, que tem sob sua responsabilidade a gestão de políticas correspondentes à maior parte do orçamento do Ministério da Saúde, compreende 42,5\% de servidores permanentes. Observa- 
se um alto percentual de trabalhadores com outros vínculos, o que é preocupante

em uma área tão estratégica, que requer conhecimento técnico especializado e mobiliza um volume expressivo de recursos. Os consultores e terceirizados representam metade dos trabalhadores dessa secretaria.

Tabela 3: Distribuição dos trabalhadores do nível central do Ministério da Saúde segundo áreas e tipos de vínculos - Brasil, 2007.

\begin{tabular}{|c|c|c|c|c|c|c|c|}
\hline \multirow[b]{2}{*}{ Unidade } & \multirow[b]{2}{*}{$\begin{array}{c}\text { Servidores } \\
\text { permanentes* }\end{array}$} & \multicolumn{4}{|c|}{ Outros Vínculos } & \multirow[b]{2}{*}{$\begin{array}{c}\text { Total } \\
\text { trabalh.*** }\end{array}$} & \multirow{2}{*}{$\begin{array}{c}\% \text { Serv. } \\
\text { perm./ } \\
\text { total }\end{array}$} \\
\hline & & $\begin{array}{c}\text { Contratos } \\
\text { temporários }\end{array}$ & Consult. & Terc. & $\begin{array}{c}\text { Total (out. } \\
\text { vinc) }\end{array}$ & & \\
\hline $\begin{array}{l}\text { Gabinete do } \\
\text { Ministro }\end{array}$ & 154 & 1 & 0 & 72 & 73 & 227 & 67,8 \\
\hline $\begin{array}{l}\text { Consultoria } \\
\text { Jurídica }\end{array}$ & 56 & 0 & 0 & 28 & 28 & 84 & 66,7 \\
\hline Sec. Executiva & 747 & 64 & 530 & 717 & 1311 & 2058 & 36,3 \\
\hline $\begin{array}{l}\text { Sec. de Atenção } \\
\text { à Saúde }\end{array}$ & 174 & 33 & 101 & 101 & 235 & 409 & 42,5 \\
\hline $\begin{array}{l}\text { Sec. de } \\
\text { Vigilância em } \\
\text { Saúde }\end{array}$ & 133 & 24 & 516 & 234 & 774 & 907 & 14,7 \\
\hline $\begin{array}{l}\text { Sec. de Gestão } \\
\text { do Trabalho e } \\
\text { da Educação em } \\
\text { Saúde }\end{array}$ & 51 & 19 & 55 & 55 & 129 & 180 & 28,3 \\
\hline $\begin{array}{l}\text { Sec. Ciênc., } \\
\text { Tecnol. e } \\
\text { Insumos } \\
\text { Estratégicos }\end{array}$ & 43 & 23 & 103 & 38 & 164 & 207 & 20,8 \\
\hline $\begin{array}{l}\text { Sec. Gestão } \\
\text { Estrat. e } \\
\text { Participativa }\end{array}$ & 111 & 4 & 0 & 248 & 252 & 363 & 30,6 \\
\hline Total Geral & 1469 & 168 & 1305 & 1493 & 2966 & 4435 & 33,1 \\
\hline
\end{tabular}

Fonte: Dados fornecidos pelo Ministério da Saúde, referentes a junho de 2007. Elaboração dos autores.

*Servidores permanentes: incluem os servidores efetivos, requisitados, nomeados sem vínculo e em exercício descentralizado.

**Total outros vínculos: é a soma dos contratos temporários, consultores e terceirizados.

${ }^{* * *}$ Total de trabalhadores: trata-se da soma dos servidores permanentes e do total outros vínculos. 
Considerando os profissionais com outros tipos de vínculos, o maior número absoluto (1.311) é encontrado na Secretaria Executiva. Isso em parte ocorre porque essa secretaria gerencia projetos que envolvem consultores e terceirizados atuantes em várias áreas do Ministério. Já o maior percentual de profissionais com outros vínculos é observado na Secretaria de Vigilância em Saúde (85,3\%). É surpreendente a baixa proporção de servidores nessa área, que é responsável por políticas tradicionais e estratégicas de Estado.

A análise dos dados relativos às novas secretarias criadas em 2003 - de Ciência, Tecnologia e Insumos Estratégicos, de Gestão do Trabalho e da Educação em Saúde e de Gestão Estratégica e Participativa - também mostra uma baixa proporção de servidores (respectivamente $21 \%$, 28\% e $31 \%$ ) e uma alta dependência de trabalhadores com outros tipos de vínculos. Destaca-se o peso dos consultores na secretaria de Ciência, Tecnologia e Insumos Estratégicos e dos terceirizados na Secretaria de Gestão Estratégica e Participativa.

Em síntese, no exame geral do quadro de trabalhadores do nível central do ministério, destaca-se a carência de servidores permanentes concursados. De 2000 a 2008, o Ministério da Saúde não conseguiu ter prioridade na realização de concursos públicos. Os primeiros concursos dos anos 2000 só ocorreram em 2006 e 2007, porém para atender às necessidades mais prementes dos hospitais federais localizados no Rio de Janeiro, permanecendo lacunas na área de gestão e finalística. O nível central do Ministério da Saúde em Brasília não foi contemplado por esses concursos. O perfil etário dos servidores do ministério, aliado à escassez de concursos, agrava a situaçãó ${ }^{4}$.

Mais recentemente, notam-se tentativas de recompor, ainda que de forma tímida e parcial, o quadro de pessoal do Ministério da Saúde, inclusive para o nível central. Em 2008, foram disponibilizadas 1000 vagas para o cargo de agente administrativo, das quais 600 seriam direcionadas à sede do ministério. Em 2009, surge a perspectiva de substituir parte dos terceirizados por meio de contratos temporários de técnicos com formação superior aprovados por processo seletivo simplificado (ESPÍRITO SANTO, 2009).

Existem ainda problemas relacionados à remuneração dos trabalhadores que atuam na sede do Ministério. Levantamentos internos sugerem que os consultores possuem remuneração bem acima da recebida pelos servidores. $\mathrm{O}$ mesmo ocorre com os terceirizados, que podem receber salários superiores aos dos profissionais de carreira, o que pode gerar constrangimentos no trabalho (SILVA, 2006). 


\section{Os trabalhadores das agências reguladoras da saúde}

No Brasil, a criação das agências reguladoras fez parte de uma reforma regulatória, e expressa uma dada perspectiva histórica. A função regulatória já existia no país no âmbito das estruturas diretas de ação do Estado. Porém, no período pósprivatização dos anos 1990, essa atribuição ganhou mais força. A maioria das agências da área de infraestrutura nasceu associada ao processo de privatização, relacionadas à busca de criação de credibilidade regulatória sobre a crescente participação privada em setores de relevância pública (PACHECO, 2006).

Já a regulação na área social abrangeria os direitos dos usuários e a qualidade dos serviços. No caso da saúde, seria importante inserir a atuação das agências - Agência Nacional de Vigilância Sanitária (ANVISA) e Agência Nacional de Saúde Suplementar (ANS) - na perspectiva de consolidação do SUS e da saúde como direito de cidadania (NOGUEIRA, 2002).

Legalmente, as agências da saúde são autarquias sob regime especial, vinculadas ao Ministério da Saúde, possuindo como atributos a independência administrativa e financeira, estabilidade dos dirigentes e poder de polícia (LUCCHESE, 2001). Porém, nos primeiros anos de funcionamento, a ANVISA e a ANS passaram por problemas financeiros, administrativos e de pessoal, com dificuldades na composição de quadros próprios de servidores?

Ainda que tais agências se assemelhem administrativamente, existem diferenças entre elas, decorrentes da história de atuação do Estado nas duas áreas. A criação da ANVISA se deu a partir de um legado político-institucional representado pela longa trajetória estatal na regulação sanitária, que desde os anos 70 vinha ocorrendo por meio da Secretaria de Vigilância Sanitária do Ministério da Saúde. Já a ANS foi criada para organizar um campo novo de ação estatal, incorporando um rol de atribuiçōes inéditas para o Ministério da Saúde (MACHADO, 2007).

A ANVISA teria como finalidade a proteção da saúde da população, por meio do controle sanitário da produção e da comercialização de produtos e serviços sujeitos à vigilância sanitária (COSTA, 2001). No que diz respeito ao quadro de pessoal, a ANVISA recebeu em 2000, pouco após a sua criação, servidores redistribuídos da extinta Secretaria de Vigilância Sanitária do Ministério, o que lhe conferiu a especificidade de iniciar o seu funcionamento com um grupo de servidores antigos. Em face da impossibilidade inicial de realização de concursos, a agência também requisitou servidores de outros órgãos, contratou profissionais 
por organismos internacionais e utilizou serviços terceirizados para dar conta de suas atribuições (ANVISA, 2007).

Como demonstra a Figura 1, a partir de 2005, com a posse dos novos concursados, ocorreu um movimento de substituição dos contratos temporários pelos novos servidores - denominados como "servidores próprios" ou "de carreira" - e a diminuição expressiva do número de servidores requisitados de outros órgãos.

Figura 1: Evolução do quadro de trabalhadores da Agência Nacional de Vigilância Sanitária- Brasil, 2000 a 2008.

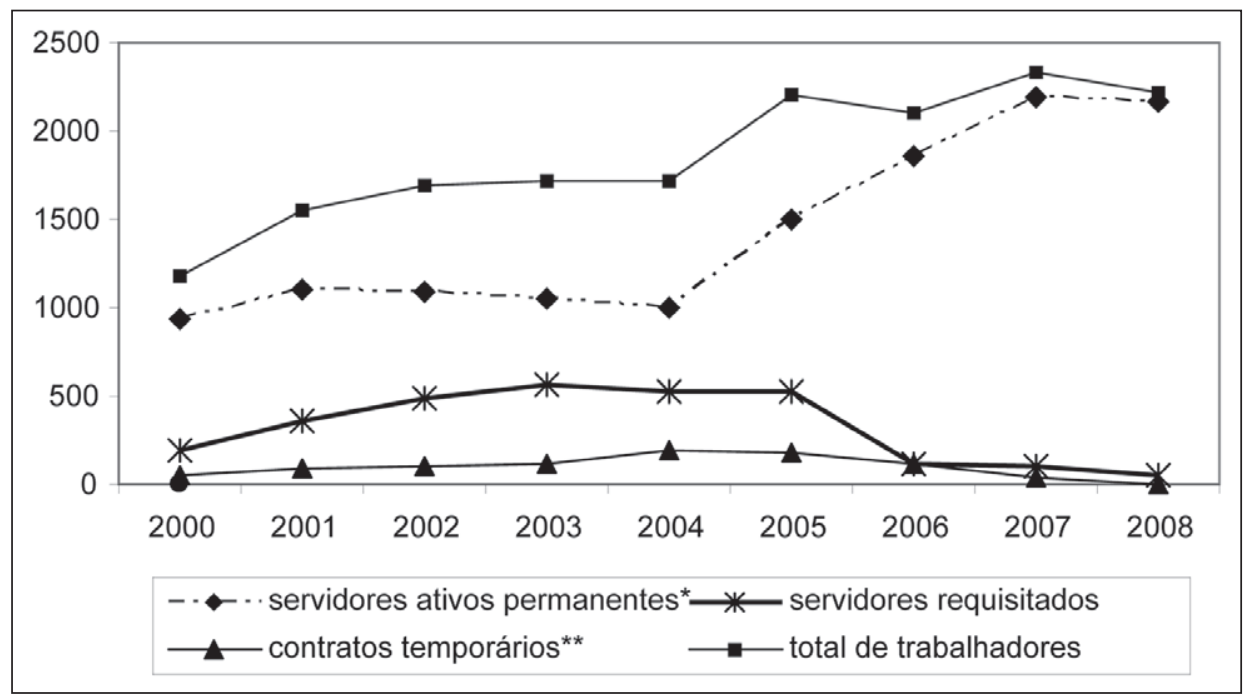

Fonte: Síntese Temática do Ministério do Planejamento, Orçamento e Gestão, dezembro de 2008. Elaboração dos autores.

*ativo permanente: incluem os servidores redistribuídos da antiga Secretaria de Vigilância Sanitária, os novos concursados, incorporados a partir de 2005 e os servidores anistiados.

${ }^{* *}$ contrato temporário: refere-se ao contratado por processo seletivo, conforme a Lei 8.745/93.

O quadro próprio cresceu muito nos anos seguintes, sendo que em 2008 os novos concursados representavam $41 \%$ dos 2.120 servidores da agência, quase alcançando o número de servidores redistribuídos da antiga Secretaria de Vigilância Sanitária (ANVISA, 2007 e 2008). Ressalte-se que existem diferenças de perfil e remuneração entre esses dois grupos de servidores. Os servidores do quadro próprio que ingressaram a partir de 2005 são em média mais jovens e recebem vencimentos básicos mais elevados do que os servidores redistribuídos da antiga Secretaria. 
Já a Agência Nacional de Saúde Suplementar (ANS) tem funções de regulação, normatização, controle e fiscalização do segmento de planos e seguros de saúde. No início de seu funcionamento, em face das dificuldades de compor um quadro próprio de servidores, contou com servidores requisitados, cedidos, pessoal sob contratos temporários e consultores. Com o passar dos anos ocorreram mudanças relevantes no perfil dos vínculos dos trabalhadores da agência, como demonstra a figura 2 .

Figura 2: Evolução do quadro de trabalhadores da Agência Nacional de Saúde Suplementar, por tipo de vínculo - Brasil, 2000 a 2008

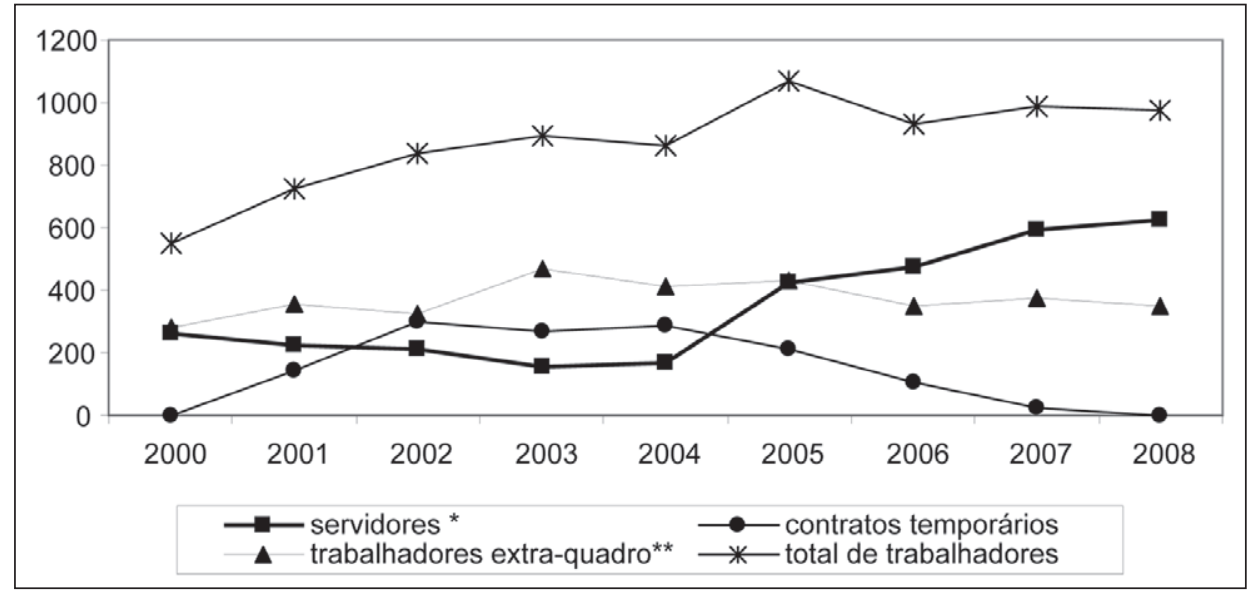

Fonte: Relatório da Agência Nacional de Saúde Suplementar de 2008. Elaboração dos autores. *servidores: incluem os ativos permanentes, requisitados, comissionados e em exercício descentralizado. *trabalhadores extraquadro: são os consultores e terceirizados.

O número total de trabalhadores da ANS evoluiu de 547 profissionais, em 2000, para 976, em 2008, representando um aumento total de $78 \%$. Enquanto nos primeiros anos predominaram os vínculos provisórios, a partir de 2005 ocorreu um aumento progressivo de servidores permanentes admitidos por concurso público, com queda no número e na proporção dos trabalhadores temporários. Entre 2000 e 2008, foram nomeados 507 concursados, representando um aumento muito significativo no quantitativo de servidores, e quase alcançando o número ideal de 515 servidores, projetado na época de criação da agência.

Ao final de 2008, os servidores representavam 64\% dos trabalhadores da agência (sendo $52 \%$ ativos permanentes), predominando profissionais do sexo 
masculino, com até 40 anos de idade e nível superior. Observe-se que ainda existe um expressivo número de profissionais terceirizados na ANS, principalmente nas áreas de informática e de apoio administrativo.

\section{Os trabalhadores da Fundação Oswaldo Cruz}

A Fundação Oswaldo Cruz (Fiocruz) é uma entidade de direito público, vinculada ao Ministério da Saúde, que desde sua criação atua no campo da pesquisa e desenvolvimento tecnológico em saúde. Caracterizou-se durante toda sua história por ser uma instituição "híbrida", direcionada tanto pela lógica acadêmica e tecnológica quanto pelos preceitos das políticas de saúde (LAMARCA, 2009). Esse hibridismo repercute em uma diversidade de funções e uma complexa estrutura organizacional, que atualmente envolve quinze unidades técnicocientíficas, um escritório internacional localizado em Moçambique (África) e unidades de apoio técnico-administrativo .

O quadro de trabalhadores da Fundação atualmente é constituído por servidores efetivos, cedidos, celetistas, nomeados para cargo em comissão, requisitados, trabalhadores contratados por empresa terceirizada, cooperativados, autônomos e participantes de programas sociais (FIOCRUZ, 2009).

A tabela 4 mostra que houve um aumento de $54,2 \%$ no total de trabalhadores da Fiocruz entre 2001 e 2008 (de 6.594 para 10.168 profissionais), decorrente principalmente do crescimento do número de servidores efetivos e de terceirizados.

O número de servidores permanentes passou de 3.129 em 2001 para 4.600 em 2008, um aumento de $47 \%$. Tal aumento foi fruto da realização de três concursos públicos nos anos de 2002, 2004 e 2006, que envolveram vagas para as áreas de assistência, pesquisa e ensino. Já o número de trabalhadores com outros vínculos cresceu $60,7 \%$ no mesmo período. Portanto, houve um aumento desse grupo maior do que o dos servidores.

Entre os trabalhadores com outros tipos de vínculos, destaca-se o aumento de $227,1 \%$ dos trabalhadores vinculados a empresas terceirizadas e a redução de $95,7 \%$ dos cooperativados. Apesar das empresas de terceirização terem absorvido parte dos profissionais cooperativados, o aumento dos terceirizados foi muito superior ao quantitativo de cooperados transferidos no período. Observase também uma diminuição dos trabalhadores "autônomos", não existindo trabalhadores classificados nessa condição em 2008. Cabe destacar que, em face 
da complexidade e diversidade interna da Fiocruz, a composição do quadro de trabalhadores por tipo de vínculo varia muito entre as unidades técnicas, o que é influenciado por sua trajetória histórica, natureza e área de atuação.

Tabela 4: Evolução do quadro de trabalhadores da Fiocruz, por tipo de vínculo Brasil, 2001 a 2008

\begin{tabular}{|c|c|c|c|c|c|c|c|c|c|}
\hline MODALIDADE & 2001 & 2002 & 2003 & 2004 & 2005 & 2006 & 2007 & 2008 & $\begin{array}{c}\% \text { VAR. } \\
2001-2008\end{array}$ \\
\hline $\begin{array}{l}\text { Servidores } \\
\text { permanentes }\end{array}$ & 3129 & 3429 & 3393 & 3391 & 3342 & 4148 & 4202 & 4600 & 47,0 \\
\hline $\begin{array}{l}\text { Trabalhadores c/ } \\
\text { outros vínculos }\end{array}$ & 3465 & 4410 & 4250 & 3852 & 4642 & 4937 & 5479 & 5568 & 60,7 \\
\hline - empresa terceirizada & 1619 & 2234 & 1590 & 2070 & 2934 & 4458 & 5223 & 5295 & 227,1 \\
\hline - cooperativa & 1319 & 1774 & 2080 & 1500 & 443 & 271 & 36 & 57 & $-95,7$ \\
\hline - autônomo & 356 & 224 & 411 & 105 & 115 & 10 & 11 & 0 & $-100,0$ \\
\hline - programa social & 171 & 178 & 169 & 177 & 1150 & 198 & 209 & 216 & 26,3 \\
\hline Total Geral & 6594 & 7839 & 7643 & 7243 & 7984 & 9085 & 9681 & 10168 & 54,2 \\
\hline $\begin{array}{l}\% \text { Servidores } \\
\text { permanentes }\end{array}$ & 46,3 & 42,7 & 43,4 & 45,9 & 41,1 & 45 & 42,8 & 44,6 & --- \\
\hline $\begin{array}{l}\text { \% Trabalhadores c/ } \\
\text { outros vínculos }\end{array}$ & 53,7 & 57,3 & 56,6 & 54,1 & 58,9 & 55 & 57,2 & 55,4 & --- \\
\hline
\end{tabular}

Fonte: Dados fornecidos pelo Serviço de Informática da DIREH/Fiocruz, baseados na fita espelho SIAPE/SGA-RH - referente a dezembro de 2008. Elaboração dos autores.

(1) Segundo dirigentes da Diretoria de Recursos Humanos, as informações sobre terceirizados passam a ser mais precisas a partir de 2005 .

(2) Servidores permanentes: incluem os servidores efetivos, cedidos, nomeados em cargo de comissão e os requisitados.

(3) Outros vínculos: estão inseridos os terceirizados, cooperativados, autônomos e profissionais de programas sociais (Federação Nacional de Educação e Integração dos Surdos - Feneis e São Martinho). Não constam os bolsistas da Fundação para o Desenvolvimento Científico e Tecnológico em Saúde (Fiotec).

Entre as unidades com maior proporção de servidores no ano de 2008 destacam-se: (a) o Instituto Oswaldo Cruz, que é a unidade mais antiga da Fiocruz e atua em pesquisa biomédica, com $72,1 \%$ de servidores entre os 824 trabalhadores; (b) o Instituto Fernandes Figueira, unidade de assistência à saúde da mulher, da criança e do adolescente, com 76,0\% de servidores entre 1.159 
trabalhadores; e (c) a Escola Nacional de Saúde Pública, que atua no ensino e pesquisa, com $83,2 \%$ de servidores entre 695 trabalhadores $^{8}$.

Já as unidades que atuam na produção de insumos são as que apresentam os menores percentuais de servidores, dependendo fortemente da inserção de trabalhadores com outros tipos de vínculos. Em 2008, dos 1.017 trabalhadores do Instituto de Tecnologia em Imunobiológicos - Biomanguinhos, somente 26,3\% eram servidores; e dos 790 trabalhadores do Instituto de Tecnologia em Fármacos - Farmanguinhos, apenas 21,1\% eram servidores.

\section{Discussão}

A pesquisa teve como propósito analisar a situação, nos anos 2000, do quadro de trabalhadores do Ministério da Saúde, das agências reguladoras da saúde (ANVISA e ANS) e da Fiocruz, que possuem um papel estratégico na formulação e regulação das políticas nacionais de saúde. O estudo partiu do pressuposto de que, mesmo com o processo de descentralização, o fortalecimento do papel federal em áreas estratégicas é fundamental para a consolidação do SUS, e de que isso requer a conformação de um quadro de servidores qualificados também na esfera federal. Assim, buscou-se analisar se, no período recente, teria havido inflexôes no que diz respeito ao perfil dos trabalhadores federais da saúde atuantes em órgãos e entidades selecionados, considerando principalmente a sua evolução quantitativa e situação de vínculo funcional.

De forma geral, observou-se de 2000 a 2008 uma inflexão na evolução do funcionalismo público em comparação com a década anterior. Tal mudança parece relacionar-se a um posicionamento do governo Lula, iniciado em 2003, de fortalecer a capacidade institucional do Estado, por meio da incorporação e valorização dos quadros da Administração Pública Federal (BRASIL, 2003a). Algumas ações concretas nesse sentido foram: a realização de concursos públicos, no intuito de recompor o quadro de servidores que se aposentaram, bem como de substituir a força de trabalho terceirizada; e as iniciativas de valorização dos servidores, por meio de qualificação profissional e melhoria nos padrões de remuneração do funcionalismo.

Tais mudanças ocorreram gradativamente e não atingiram todas as áreas da administração na mesma intensidade. $\mathrm{O}$ incremento de servidores do Executivo federal foi expressivo, porém a área da saúde teve um crescimento do número de 
servidores ativos abaixo do aumento médio do conjunto das áreas e bem inferior

ao da área da educação, por exemplo. A ampliação dos servidores federais da educação pode refletir a valorização do ensino superior nesse governo, que lançou projetos de expansão dos campi e das vagas nas universidades federais, o que implicou na realização de muitos concursos públicos. Nesse sentido, o aumento de servidores veio atender a uma expansão da prestação direta de serviços de educação superior.

Já na saúde, apesar das necessidades de fortalecimento da coordenação nacional do SUS em vários âmbitos, não se observa de forma tão nítida a adoção de uma política ativa e integrada do Governo Federal de incorporação de quadros qualificados para o conjunto do setor. Isso pode explicar em parte a tímida expansão do número de servidores federais da saúde no período, reiterando a fragilidade histórica das carreiras federais nessa área.

Ainda que a prestação federal direta de serviços tenha se retraído no período da implantação do SUS - o que era coerente com a agenda da reforma sanitária e o processo de descentralização - o que chama a atenção é a precariedade da situação de vínculos dos trabalhadores federais mesmo em áreas técnicas estratégicas para a condução e coordenação nacional da política de saúde.

Assinale-se que a governabilidade do setor saúde sobre a definição de políticas de pessoal é limitada. Os servidores da saúde se inserem no Sistema de Pessoal Civil da Administração Federal, cuja política é definida pelo Ministério do Planejamento, Orçamento e Gestão. Isso faz com que boa parte das decisões e da gestão de pessoal fique fora da esfera setorial, que deve se submeter a um conjunto de regras estabelecidas quanto à estrutura do quadro, carreiras, realização de concursos e remuneração, entre outros aspectos.

Ao se considerar separadamente a situação dos trabalhadores atuantes nos órgãos e as entidades da saúde - o nível central do Ministério da Saúde em Brasília, as duas agências reguladoras da saúde e a Fundação Oswaldo Cruz percebem-se diferenças importantes.

No que se refere ao nível central do Ministério da Saúde, até o ano de 2008, as formas predominantes de inserção de trabalhadores foram os contratos temporários, a terceirização e os consultores. A proporção de servidores no quadro geral de trabalhadores, no ano de 2007, diferia entre secretarias e departamentos do Ministério, mas em geral era baixa, mesmo em áreas estratégicas. Essa 
preponderância de trabalhadores com vínculos variados (e transitórios, em sua maioria) na sede do ministério pode ter relação com elementos históricos - como a conformação do ministério a partir de uma diversidade de organizaçôes distintas - e com as dificuldades de redefinição de um papel positivo federal no contexto de implantação do SUS. A situação atual do quadro de trabalhadores traz desafios no que diz respeito à questão remuneratória e, sobretudo, à continuidade das políticas nacionais. Recentemente, criaram-se expectativas de que a reestruturação de carreiras na área social proposta pelo Governo Federal venha a favorecer a conformação de quadros qualificados no Ministério da Saúde?.

Já os quadros de trabalhadores das agências reguladoras da saúde (ANVISA e ANS) apresentaram uma evolução diferenciada no período estudado. Tais entidades foram criadas no final dos anos 1999 e início dos anos 2000, em consonância com as diretrizes da reforma do Estado do governo Fernando Henrique Cardoso. Ao mesmo tempo, representaram movimentos de fortalecimento da atuação do Estado em áreas críticas para a saúde, que envolvem muitos interesses de mercado (a vigilância sanitária e a regulação do segmento de planos e seguros de saúde).

A análise da evolução recente do quadro de trabalhadores das agências sugere que elas tiveram um tratamento diferenciado em relação à sede do Ministério da Saúde, por meio da realização de concursos para a conformação de quadros próprios. No entanto, também foram observadas diferenças na composição do quadro de trabalhadores das duas agências, fruto das especificidades da trajetória das áreas que constituem seus objetos de intervenção.

No início dos anos 2000, as agências utilizaram diversos tipos de vínculos temporários para a execução de suas funções, o que gerou instabilidade e maior rotatividade de pessoal. A partir de 2005, tal situação começa a se modificar, com a realização de concursos para a conformação de quadros especializados para atuar nas agências.

$\mathrm{Na}$ ANVISA, o quantitativo de novos servidores concursados aumentou progressivamente nos anos seguintes, aproximando-se do número de servidores advindos da Secretaria de Vigilância Sanitária. Persistem, no entanto, diferenças importantes entre esses dois grupos de servidores, no que concerne ao perfil etário, profissional e nível de remuneração. Na ANS, a incorporação de novos concursados para composição da carreira própria a partir de 2005 levou à redução dos trabalhadores com contratos temporários que predominaram nos primeiros 
anos de seu funcionamento. Porém, nota-se a manutenção de um grande número de terceirizados na agência, principalmente na área administrativa.

Já a Fundação Oswaldo Cruz apresenta uma trajetória histórica e um perfil institucional bastante diferenciados, caracterizando-se por grande diversidade de atribuições. A Fiocruz também conseguiu negociar com o Ministério do Planejamento, nos anos 2000, concursos para reposição de seu quadro de servidores, com ênfase nos cargos estratégicos de nível superior, nas áreas de pesquisa e produção e na substituição de terceirizados. Porém, a pesquisa apontou que, além do incremento do número de servidores em função dos concursos, houve um aumento expressivo dos trabalhadores terceirizados no período estudado.

Em síntese, a pesquisa mostrou que o nível central do Ministério da Saúde foi o menos priorizado com concursos públicos entre 2000 e 2008. As agências da saúde conseguiram compor quadros de servidores próprios e a Fiocruz foi contemplada com a inserção de novos concursados para recompor, em parte, seu quadro de servidores. Além disso, ocorreu a valorização dessas três entidades, por meio de aumentos salariais. Tal situação relaciona-se à trajetória de cada organização e depende do contexto e escolhas políticas do período, que podem impactar na conformação e evolução do quadro de trabalhadores dos órgãos e entidades públicas. Por outro lado, problemas relacionados à inserção dos trabalhadores (diversidade de situações, instabilidade dos vínculos) ainda estão presentes em todas as unidades estudadas, embora as atinjam de maneira diferenciada. Apesar de um esforço recente do Governo Federal em substituir os trabalhadores com vínculos precários, estes ainda persistiam, em 2008, com certa importância nas unidades analisadas.

No que diz respeito à gestão federal do trabalho em saúde, os resultados sugerem uma série de desafios. O primeiro é a necessidade de aprofundamento da discussão do papel estratégico do Ministério da Saúde e das entidades vinculadas à luz dos princípios do SUS. Um segundo é a premência de recomposição do quadro de trabalhadores federais da saúde de forma efetiva e estável, por meio da redução dos vínculos precários e aumento dos servidores de carreira. Por fim, ressalte-se a importância de investimento em carreiras próprias para a área social, especialmente a da saúde, com vistas à constituição de uma burocracia sólida e competente para lidar com a complexidade da condução nacional da política de saúde em um país imenso, federativo e desigual como o Brasil. 


\section{Agradecimentos}

A pesquisa contou com apoio financeiro do Conselho Nacional de Desenvolvimento Científico e Tecnológico do Brasil - CNPq, da Fundação Carlos Chagas de Amparo à Pesquisa do Estado do Rio de Janeiro - FAPERJ e do Programa Estratégico de Apoio à Pesquisa em Saúde - PAPES/Fiocruz.

\section{Referências}

AGÊNCIA NACIONAL DE SAÚDE SUPLEMENTAR. Relatório de gestão: exercício de 2008. Rio de Janeiro: 2009. Disponível em:<http://www.ans.gov.br>. Acesso : 27 abr. 2009. AGÊNCIA NACIONAL DE VIGILÂNCIA SANITÁRIA. Resolução da Diretoria Colegiada no 102/2006. Brasília: 2006. Disponível em: <http://www.anvisa.gov.br/ publicacoes>. Acesso : 27 abr. 2009.

Relatório anual de atividades: exercício 2007. Brasília: 2008. Disponível em: <http://www.anvisa.gov.br>. Acesso : 27 abr. 2009.

Relatório anual de atividades: Exercício 2008. Brasília: 2009. Disponível em: <http://www.anvisa.gov.br>. Acesso : 27 abr. 2009.

BRASIL. Decreto n ${ }^{\circ}$ 4.726, de 09 de junho de 2003. Aprova a estrutura regimental e o quadro demonstrativo dos cargos em comissão e das funções gratificadas do Ministério da Saúde, e dá outras providências. Diário Oficial [da] República Federativa do Brasil, Poder Executivo, Brasília, DF, 10 jun. 2003. p. 12. Disponível em:<http://www.planalto.gov.br/ ccivil_03/decreto/2003/D4726.htm>. Acesso em: 2 maio 2009.

Ministério da Saúde. Diagnóstico do quadro de pessoal do Ministério da Saúde: 2007. Brasília, DF, 2009.

Ministério da Saúde. Diagnóstico do quadro de pessoal do Ministério da Saúde: 2008. Brasília, DF, 2009a.

. Ministério da Saúde. Observatório de Conjuntura da Política de Saúde. Boletim Ministério da Saúde de setembro a novembro de 2008. Brasília, DF, 2009b. Disponível em: <http://www4.ensp.fiocruz.br/conjuntura>. Acesso : 13 jan. 2010.

- Ministério do Planejamento, Orçamento e Gestão. Boletim Estatístico de Pessoal. Brasília, DF, 2008a. Disponível em: <http://www. servidor.gov.br/ publicacao/ boletimestatistico/bolestatistico.htm>. Acesso : 13 jan. 2009.

- Ministério do Planejamento, Orçamento e Gestão. Evolução setorial da força de trabalho no governo Lula. Comunicado Seges, Brasília, DF, n. 1, 2009c.

- Ministério do Planejamento, Orçamento e Gestão. Síntese temática. Quadro

da força de trabalho da Agência Nacional de Vigilância Sanitária. Brasília, DF, 2008b. Disponível em: <http://www.planejamento.gov.br>. Acesso: 01 set. 2009. 
força de trabalho do Ministério da Saúde. Brasília, DF, 2008c. Disponível em: <http:// www.planejamento.gov.br>. Acesso: 01 abr. 2009.

- Ministério do Planejamento, Orçamento e Gestão. Secretaria de Gestão. Gestão pública para um Brasil de todos: um plano de gestão para o Governo Lula. Brasília, DF, 2003a. 30p. Disponível em:<http://www.planejamento.gov.br>. Acesso: 13 jan. 2009.

- Senado Federal. Base de dados Sistema de Informaçôes sobre Planos de Orçamento Público - SIGA Brasil. Brasília, DF, 2008d. Disponível: <http://www9.senado.gov.br/prtal/ page/portal/orçamento_senado/SigaBrasil>. Acesso em: 18 mar. 2009.

COSTA, E. A. Políticas de vigilância sanitária: balanço e perspectivas. In: CONFERÊNCIA NACIONAL DE VIGILÂNCIA SANITÁRIA, 1. Cadernos de Textos. Brasília: Agência Nacional de Vigilância Sanitária, 2001. p. 37-52.

ESPIRITO SANTO, E. M. Saúde inicia recuperação da força de trabalho. MS Informa, Brasília, jan. 2009. Disponível em: <http://dtr2001.saude. gov.br/ascp,/edicao_3/novos_ servidores.html>. Acesso: 05 jun. 2009.

EVANS, P. O Estado como problema e solução. Lua Nova. n. 28/29, p. 107-156, 1993.

FUNDAÇÃO OSWALDO CRUZ. Unidades da Fiocruz. Rio de Janeiro: 2009. Disponível em: <http://www.fiocruz.br>. Acesso: 20 nov. 2009.

. Diretoria de Recursos Humanos. Tabelas elaboradas pelo SEINFO/DIREH, com dados do quantitativo, sexo, faixa etária e escolaridade dos servidores da Fiocruz, no período de 2000 a 2008. Rio de Janeiro, 2009.

- Vice-Presidência de Ensino e Recursos Humanos. Termo de referência de gestão de recursos humanos: documento preliminar a ser submetido à análise da Câmara Técnica de Recursos Humanos. Rio de Janeiro, 2001.

HALL, P. A.; TAYLOR, R. C. R. As três versões do neoinstitucionalismo. Lua Nova, n. 58, p. 193-224, 2003.

HAMILTON, W.; FONSECA, C. Política, atores e interesses no processo de mudança institucional: a criação do Ministério da Saúde em 1953. História, Ciências, Saúde Manguinhos, Rio de Janeiro. v. 10, n. 3, p. 791-825, 2003.

JUSTO, A. O processo de intervenção federal no município do Rio de Janeiro: possibilidades de inovação na gestão e a condução dos recursos humanos nos hospitais refederalizados do Rio de Janeiro. 2008. 175 f. Dissertação (Mestrado em Saúde Pública) - Escola Nacional de Saúde Pública. Fundação Oswaldo Cruz, Rio de Janeiro. 2008.

LAMARCA, I. C. S. A. Reformas administrativas e políticas de incorporação da força de trabalho no governo central brasileiro (1995-2006). 2009. 110 f. Tese (Doutorado em Saúde Pública) - Escola Nacional de Saúde Pública. Fundação Oswaldo Cruz, Rio de Janeiro. 2009. 
LUCCHESE, G. Globalização e regulação sanitária: os rumos da vigilância sanitária no Brasil. 2001. 245 f. Tese (Doutorado em Saúde Pública) - Escola Nacional de Saúde Pública. Fundação Oswaldo Cruz, Rio de Janeiro. 2001.

MACHADO, C. V. Direito universal, politica nacional: o papel do Ministério da Saúde na política de saúde brasileira de 1990 a 2002. Rio de Janeiro: Museu da República, 2007.

MORAES, M. V. E.; SILVA, T. F.; COSTA, P. V. O mito do inchaço da força de trabalho do executivo federal. Respvblica. v. 7, n. 2, p. 1-17, 2009.

NOGUEIRA, R. P. As agências reguladoras da saúde e os direitos sociais. Boletim de Políticas Sociais - Acompanhamento e Análise. Brasília, DF, n. 5, p. 101-105, ago. 2002. Disponível em: http://www.buscalegis.ufsc.br/ revistas/index.php/ buscalegis/article/ viewFile/30786/30106. Acesso: 28 jun. 2010.

NUNES, E. A gramática política do Brasil: clientelismo e insulamento burocrático. Rio de Janeiro: ENAP, 1997.

PACHECO, R. S. Regulação no Brasil: desenho das agências e formas de controle. RAP. v. 40, n. 4, p. 523-543, 2006.

PECI, A. Reforma Regulatória brasileira dos anos 90 à luz do modelo de Kleber Nascimento. RAC. v. 11, n. 1, p. 11-30, 2007.

PIERANTONI, C. R. As Reformas do Estado, da saúde e recursos humanos: limites e possibilidades. Ciênc. saúde coletiva. v. 6, n. 2, p. 341-360, 2001.

SANTOS, W. G. O ex-leviatã brasileiro do voto disperso ao clientelismo concentrado. Rio de Janeiro: Civilização Brasileira, 2006.

SILVA, R. C. G. Recursos humanos no Ministério de Saúde: uma análise. 2006. 48 f. Trabalho de conclusão de curso (Especialização em Saúde Pública) - Escola Nacional de Saúde Pública. Fundação Oswaldo Cruz, Rio de Janeiro. 2006.

UNIVERSIDADE DE BRASÍLIA. Subsídios para o plano de reordenamento dos recursos humanos no âmbito do Ministério da Saúde: tendências e situação dos recursos humanos do poder executivo federal, 1990-2004. In: Relatório da UNB-DF; CEAM; NESP; POLRHS. Brasília, 2004.

VIANA, A. L. A.; MACHADO, C. V. Proteção social em saúde: um balanço dos 20 anos do SUS. Physis. v. 18, n. 4, p. 645-684, 2008.

VIANA, M. Governo mantém 25 mil terceirizados: um ano e dois meses depois de acordo com MP, problema no serviço público continua. Jornal o Globo, Rio de Janeiro, p. 3, 24 jan. 2009.

WAHRLICH, B. M. S. Reforma Administrativa na Era Vargas. Rio de Janeiro: FGV, 1983. 
${ }^{1}$ O Ministério da Saúde foi criado em 1953, a partir do desmembramento do Ministério da Educação e Saúde Pública, que existia desde 1930. No entanto, dada a trajetória dual do sistema de saúde brasileiro, somente com a implantação do SUS e a incorporação do Instituto Nacional de Assistência Médica da Previdência Social -INAMPS em 1990, o Ministério da Saúde assumiu a responsabilidade pelo comando unificado da política nacional de saúde. A respeito da criação do Ministério da Saúde, ver Hamilton e Fonseca (2003). Para uma análise da atuação do Ministério nos anos 1990, consultar Machado (2007).

${ }^{2}$ Os trabalhadores dos hospitais federais foram objeto de estudo recente de Justo (2008). Já os trabalhadores lotados na Fundação Nacional da Saúde/ FUNASA não foram incluídos na pesquisa, pelo fato de essa fundação, no momento do estudo, estar passando por mudanças. Segundo o boletim do Observatório de Conjuntura da ENSP (2009), a partir de 2003, houve redução das funções da FUNASA com a transferência da área de vigilância epidemiológica para a Secretaria de Vigilância à Saúde. No $2^{\circ}$ semestre de 2008, ocorreu a discussão sobre a criação de uma nova Secretaria no Ministério da Saúde que, caso efetivada, incorporaria atribuições da FUNASA, com redução adicional de suas funções.

${ }^{3}$ http://www9.senado.gov.br/portal/page/portal/orcamento_senado/SigaBrasil

${ }^{4}$ Segundo dados oficiais, em 2008, 61\% dos servidores ativos do Ministério da Saúde possuíam mais de 50 anos de idade. Ao realizar a previsão de aposentadoria dos servidores, o Ministério inferiu que em cinco anos 17.942 servidores poderiam se aposentar, o que representava $29 \%$ do total. Em dez anos este número seria mais que o dobro, ou seja, 26.079 servidores se aposentariam, significando a perda de $57 \%$ do total de servidores ativos do Ministério. A estimativa incluiu os servidores do Ministério da Saúde da sede; dos núcleos estaduais e DATASUS/RJ; centros e institutos de pesquisa - PA/RJ; hospitais e institutos do Rio de Janeiro; cedidos SUS; e cedidos a outros órgãos. Como referência de cálculo foi considerado o tempo mínimo para aposentadoria previsto em lei: para os homens, 60 anos de idade e 35 anos de contribuição; para as mulheres, 55 anos de idade e 30 anos de contribuição (BRASIL.MS, 2008).

${ }^{5}$ Este acontecimento foi decorrente em parte da impugnação pelo Supremo Tribunal Federal da composição do quadro próprio, através de uma Ação Direta de Inconstitucionalidade direcionada à Lei das Agências no 9.986/2000, proposta pelo Partido Comunista do Brasil e pelo Partido dos Trabalhadores. Esta Lei dispunha sobre o quadro próprio de servidores e sua contestação ancorouse no argumento de que a mesma estivesse em desacordo com a Emenda Constitucional no 19 , que estabelecia as funções de fiscalização e regulação como atividades típicas de Estado (PECI, 2007).

${ }^{6}$ Segundo a RDC 102/2006, que trata da gestão de recursos humanos da ANVISA, os servidores redistribuídos da extinta Secretaria de Vigilância Sanitária foram integrados à Agência pela Lei 10.884/2004, na forma de "Quadro Específico" (ANVISA, 2006).

${ }^{7}$ A estrutura organizacional da Fiocruz compreende ainda a presidência, cinco vice-presidências, um Conselho Deliberativo e vários órgãos de assistência direta à presidência. (FIOCRUZ, 2009).

${ }^{8}$ Segundo dados oficiais preparados e fornecidos diretamente pela Diretoria de Recursos Humanos da Fundação Oswaldo Cruz, a pedido das pesquisadoras, que apresentam a distribuição dos trabalhadores por tipos de vínculos nas diversas unidades da Fiocruz.

${ }^{9}$ O governo propôs um Projeto de Lei que está em tramitação no Senado e prevê a criação de 2.400 cargos de Analista Técnico de Políticas Sociais na carreira de Desenvolvimento de Políticas Sociais. Segundo Moraes, Silva e Costa (2009), a nova carreira abrangeria atividades de assistência técnica, monitoramento e avaliação de programas e projetos na área social. Há expectativas por dirigentes da área de Recursos Humanos do Ministério da Saúde de que a nova carreira contemple a inserção, por meio de concurso público, de servidores de nível superior e de formação especializada, que poderiam substituir parte dos consultores atuantes no nível central do ministério. 


\section{The federal health work force in Brazil: an analysis in the context of the 2000's}

This paper analyzes the work force of the Brazilian Ministry of Health and associated entities -the health regulatory agencies and the Oswaldo Cruz Foundation -from 2000 to 2008, focusing on the quantitative evolution and types of employment relation. The methods involved a bibliographical review, documental analysis and analysis of primary and secondary data. The results suggest that since 2003, there has been an increase in civil service admissions. However, the increase in active federal health workers was lower than the average increase of the Federal Executive. Differences were found in the staffing situations of the Ministry of Health and of the associated entities. The central office of the Ministry benefitted only slightly from the civil service admissions and remained dependent on professionals hired as consultants or by temporary contracts. The health regulatory agencies have benefitted from civil service admission examinations since 2005 , but at the end of the period there was still a large proportion of workers employed under alternative types of engagement. Meanwhile at Fiocruz, despite the increase in the number of civil servants, there was a greater increase in the number of workers employed under other types of contracts. Finally, the challenges involved in forming a stable and adequate federal work force are discussed, considering that in Brazil the federal government plays a fundamental role in consolidating the Unified Health System (SUS).

> Key words: health policy; federal civil service; health workers; Ministry of Health; health regulatory agencies; Oswaldo Cruz Foundation. 